\title{
Macrophages and Dendritic Cells for Treating Kidney Disease
}

\author{
Q.Cao D. Zheng Y.P. Wang D.C.H. Harris
}

Centre for Transplantation and Renal Research, Westmead Millennium Institute at University of Sydney, Sydney, N.S.W., Australia

\section{Key Words}

Macrophages • Dendritic cells · Renal architecture

\begin{abstract}
Based on new understanding of the diverse biological functions of macrophages and dendritic cells (DC), the focus of studies on these cells has been expanded from their pathogenic role in renal diseases to include their potential to regulate inflammation and restore renal architecture and function. By exploiting their regulatory function, macrophages or DC have been used to treat experimental renal disease following their adoptive transfer. This review summarizes current progress in the therapeutic use of macrophages and $D C$ in renal diseases. Key issues for ongoing research are discussed.

Copyright $\odot 2010$ S. Karger AG, Basel
\end{abstract}

\section{Introduction}

Macrophages and dendritic cells (DC) originate from a common progenitor mononuclear phagocyte system in bone marrow. Both macrophages and DC are antigenpresenting cells and play an important role in initiating innate immune responses and generating adaptive immunity. Macrophages and DC share many surface markers and properties essential to defense and tissue remodeling and repair, yet until now these cells have been regarded as relatively discrete, with macrophages being a key component of the innate immune system and DC interfacing with the adaptive immune system and modulating immune responses. Both macrophages and DC are found in normal renal tissue and in various renal diseases where they are involved in initiation and progression of renal diseases. Macrophages comprise a diverse population of cells with various roles in development, progression and recovery of renal diseases. DC can activate naïve $\mathrm{T}$ cells and initiate primary immune responses, especially in immune-mediated renal diseases. Macrophages and DC communicate with each other via direct cell-cell interactions or by their production of inflammatory signals. In the past decade, the focus of studies has expanded to include the potential benefits of macrophages and DC in immune regulation and tissue repair. Because of their dynamic nature and ability to respond to microenvironmental stimuli and interact with neighboring cells, macrophages and DC can be modulated to regulatory and anti-inflammatory phenotypes which hold therapeutic potential.

\section{KARGER}

Fax +4161306 1234 E-Mail karger@karger.ch www.karger.com (c) 2010 S. Karger AG, Basel

$1660-2129 / 11 / 1173-0047 \$ 38.00 / 0$

Accessible online at:

www.karger.com/nee
Qi Cao, MD

Centre for Transplantation and Renal Research, Westmead Millennium Institute

University of Sydney, Darcy Road, Westmead

Sydney, N.S.W. 2145 (Australia)

Tel. +61 29845 8906, E-Mail xxcaoqi@yahoo.com.cn 
Table 1. Published studies of regulatory macrophages and DC used as immunotherapy in kidney disease

\begin{tabular}{llc}
\hline Type of cell & Animal model & $\begin{array}{c}\text { Reference } \\
\text { No. }\end{array}$ \\
\hline Macrophages activated by IL-4 and IL-13 (splenic, $\mathrm{M}_{2 \mathrm{a}}$ macrophages) & murine Adriamycin nephropathy \\
Macrophages activated by IL-10 and TGF- $\beta$ (splenic, $\mathrm{M}_{2 \mathrm{c}}$ macrophages) & $\begin{array}{l}\text { murine Adriamycin nephropathy } \\
\text { rat anti-GBM }\end{array}$ & 2 \\
IL-1ra-transfected macrophages & nephrotoxic nephritis & 3 \\
IL-4 transfected macrophages & nephrotoxic nephritis & 4 \\
IL-10-transfected macrophages & nephrotoxic nephritis \\
Bone-marrow-derived macrophages transduced with IкB & murine Adriamycin nephropathy \\
Plasmacytoid DC (splenic) & 6 & 5 \\
\hline
\end{tabular}

$\mathrm{IL}=$ Interleukin; TGF = transforming growth factor; IL-1 ra = interleukin 1 receptor antagonist; GBM = glomerular basement membrane; I $\mathrm{B}=$ inhibitory protein $\kappa \mathrm{B}$.

\section{Macrophages as a Therapeutic Approach}

Based on a new understanding of their diverse functions, macrophages are no longer regarded merely as effectors of injury, but also as potential therapeutic tools to regulate inflammation and restore renal architecture and function. Adoptive transfer of macrophages with suppressive features has been applied to the treatment of experimental kidney diseases. Macrophages may be modulated to a protective phenotype by either genetic manipulation or by cytokines (table 1).

\section{Genetic Manipulation of Macrophages}

Activity of macrophages can be manipulated by transfer of suppressive genes using viral vectors. Yokoo et al. [3] used an adenovirus vector expressing interleukin 1 receptor antagonist (IL-1ra) in bone-marrow-derived $\mathrm{CD} 11 \mathrm{~b}+\mathrm{CD} 18+$ cells. When administered to mice with anti-glomerular-basement-membrane (GBM) disease, these IL-1ra-transfected cells tracked to glomeruli, increasing local glomerular expression of IL-1ra, and then translocated to the tubulointerstitial compartment to significantly reduce glomerular and tubulointerstitial injury for up to 14 days. To prolong the therapeutic effect, the investigators also reconstituted bone marrow with stem cells transduced with an adenovirus vector expressing IL$1 \mathrm{ra}$ in the anti-GBM model. In this study stem-cell-based gene therapy conferred resistance to glomerular inflammation in experimental anti-GBM disease, with a therapeutic effect that lasted at least 16 weeks [7].

Kluth et al. [4] showed that macrophages transfected with recombinant adenovirus expressing IL-4 localized efficiently to inflamed glomeruli of rats with nephrotox- ic nephritis after direct injection into the renal artery and reduced inflammatory cell infiltration and the degree of glomerular injury. Interestingly, unilateral intra-arterial injection of IL-4-expressing macrophages reduced glomerular injury in both kidneys. Systemically injected IL4-transfected macrophages had no effect. The same group then performed a similar experiment using bonemarrow-derived macrophages transfected with adenovirus expressing IL-10 and achieved comparable results [5].

Wilson et al. [6] showed that bone-marrow-derived macrophages transduced with inhibitor protein $\kappa B$, which blocks nuclear factor $\kappa \mathrm{B}$ proinflammatory signaling, reduced IL-12 and tumor necrosis factor $\alpha$ synthesis and nitric oxide generation of macrophages stimulated with lipopolysaccharide, and increased IL-10 synthesis. These reoriented macrophages also significantly reduced glomerular infiltration and activation of host macrophages and blocked the development of renal injury in nephrotoxic nephritis. These studies demonstrated that nuclear-factor- $\mathrm{\kappa B}$-blocked macrophages release IL-10 after activation, and that such macrophages do not become classically activated after infusion into nephritic kidneys but instead have a dominant anti-inflammatory effect and attenuate injury.

In addition to their protective effects against renal injury, a unique advantage of genetically engineered macrophages is their ability to deliver genes specifically to sites of inflammation by following natural inflammatory chemotactic signals. Therefore this approach can be injury or inflammatory site specific, in contrast to other types of cell-based therapy. Although genetic manipulation of macrophages has been successfully applied to prevent renal injury in animal models, major obstacles to 
Table 2. Macrophage activation states and functions

\begin{tabular}{|c|c|c|c|c|}
\hline & \multicolumn{4}{|l|}{ Macrophage phenotype } \\
\hline & $\mathrm{M}_{1}$ & $\mathrm{M}_{2 \mathrm{a}}$ & $\mathrm{M}_{2 \mathrm{~b}}$ & $\mathrm{M}_{2 \mathrm{c}}$ \\
\hline Stimuli & IFN- $\gamma$, TLR/IL-1R ligand & IL-4, IL-13 & $\begin{array}{l}\text { Immune complex } \\
+ \text { TLR/IL-1R ligand }\end{array}$ & $\begin{array}{l}\text { IL-10, TGF- } \beta \text {, } \\
\text { glucocorticoids, apoptotic cells }\end{array}$ \\
\hline Surface markers & MHC-II, CD86 & $\begin{array}{l}\text { Mannose receptor, scavenger receptor, } \\
\text { CD163 }\end{array}$ & MHC-II, CD86 & $\begin{array}{l}\text { Mannose receptor, B7-H4, SLAM } \\
\text { (CD150) }\end{array}$ \\
\hline $\begin{array}{l}\text { Cytokine and } \\
\text { inflammatory profile }\end{array}$ & $\begin{array}{l}\text { IL-1, IL-6, IL-12, TNF- } \alpha \text {, } \\
\text { CCL2, CXCL9, CXCL10, } \\
\text { CXCL11, iNOS }\end{array}$ & $\begin{array}{l}\text { CCL17, CCL18, arginase 1, Ym1, } \\
\text { FIZZ1/RELM } \alpha \text {, stabilin 1, IGF-1, } \\
\text { factor XIIIA }\end{array}$ & IL-10, CCL1, SPHK1 & $\begin{array}{l}\text { IL-10, TGF- } \beta \text {, CCL16, CCL18, } \\
\text { arginase } 1\end{array}$ \\
\hline Function & $\begin{array}{l}\text { Th1 responses, tumor } \\
\text { resistance }\end{array}$ & Th2 responses, tissue repair & $\begin{array}{l}\text { Immunoregulation, } \\
\text { Th2 activation }\end{array}$ & $\begin{array}{l}\text { Immunoregulation, matrix } \\
\text { deposition, tissue remodeling }\end{array}$ \\
\hline
\end{tabular}

IFN- $\gamma=\gamma$-Interferon; IL-1R = interleukin 1 receptor; IGF-1 = insulin-like growth factor 1; iNOS = inducible nitric oxide synthase; MHC-II $=$ major histocompatibility complex class II; RELM $\alpha=$ resistin-like molecule $\alpha$; SLAM = signaling lymphocytic activation molecule; SPHK1 = sphingosine kinase $1 ;$ TLR $=$ Toll-like receptor; TNF- $\alpha=$ tumor necrosis factor $\alpha ;$ Ym1 $=$ a chitinase-like protein; FIZZ1 = a resistin-like protein markedly induced by IL-4 and IL-13.

clinical application of this technology include the danger of viral vectors and difficulty in controlling the level of gene expression in vivo.

\section{Cytokine Alteration of Macrophage Phenotype}

Although widely recognized as contributors to the pathogenesis of various renal diseases, macrophages also play beneficial roles in angiogenesis, wound healing and tissue remodeling through their secretion of anti-inflammatory cytokines or regulation of $\mathrm{T}$ cell function. These protective macrophages, also called as alternatively activated macrophages $\left(\mathrm{M}_{2}\right.$ macrophages), consist of at least 3 groups: $\mathrm{M}_{2 \mathrm{a}}$ macrophages induced by IL- 4 and/or IL-13, $\mathrm{M}_{2 \mathrm{~b}}$ macrophages by immune complexes with lipopolysaccharide, and $\mathrm{M}_{2 \mathrm{c}}$ macrophages by IL-10 and/or transforming growth factor (TGF) $\beta$ (table 2).

We have shown that adoptive transfer of $\mathrm{M}_{2 \mathrm{a}}$ macrophages is renoprotective in immunodeficient (SCID) mice with Adriamycin nephropathy (AN). Macrophages freshly isolated from murine spleen and cultured in the presence of IL- 4 and IL-13 were skewed towards an antiinflammatory phenotype (designated $\mathrm{M}_{2 \mathrm{a}}$ macrophages) [1]. Macrophages were transfused into mice 5 days after Adriamycin injection, when renal injury is already established in this model. $\mathrm{M}_{2 \mathrm{a}}$ macrophages significantly protected AN mice against both structural and functional renal injury. $\mathrm{M}_{2 \mathrm{a}}$ macrophages localized preferentially to the area of injury, and the protective effect of $\mathrm{M}_{2 \mathrm{a}}$ macrophages was associated with reduced accumulation and downregulated inflammatory cytokine expression of host-infiltrating macrophages. This study demonstrated a lymphocyte-independent mechanism of protection by $\mathrm{M}_{2 \mathrm{a}}$ macrophages and provided direct evidence that ex vivo modulation of macrophages by cytokines to an antiinflammatory phenotype can be an effective strategy for treating experimental chronic inflammatory renal disease. Similarly, we showed that adoptive transfer of $\mathrm{M}_{2 \mathrm{a}}$ macrophages was protective against renal structural and functional injury in immunocompetent mice with AN (fig. 1).

Recently, our group has identified B7-H4 as a specific functional biomarker of $\mathrm{M}_{2 \mathrm{c}}$ macrophages [2]. $\mathrm{B} 7-\mathrm{H} 4$ is a recently discovered inhibitory member of the B7 family. Its expression has been reported in tumor-associated macrophages in human ovarian carcinoma [8]. It has been shown that regulatory $\mathrm{T}$ lymphocytes $\left(\mathrm{T}_{\text {reg }}\right)$ can convey suppressive activity to macrophages by stimulating B7-H4 expression through IL-10. A striking finding in another study from our group was that $\mathrm{M}_{2 \mathrm{c}}$ macrophages, but not $\mathrm{M}_{2 \mathrm{a}}$ macrophages, could convey suppressive activity to T cells via B7-H4, resulting in induction of $\mathrm{T}_{\text {reg. }}$. Thus, B7-H4 is potentially a specific and functional biomarker of $\mathrm{M}_{2 \mathrm{c}}$ macrophages [2].

Adoptive transfer of $\mathrm{M}_{2 \mathrm{c}}$ macrophages significantly reduced tubular atrophy, interstitial expansion and glomerulosclerosis in $\mathrm{AN} . \mathrm{M}_{2 \mathrm{c}}$ macrophages also reduced proteinuria and increased creatinine clearance significantly. It appeared that $\mathrm{M}_{2 \mathrm{c}}$ macrophages were more effective than $\mathrm{M}_{2 \mathrm{a}}$ macrophages in reducing renal histological and functional injury. The greater potency of $\mathrm{M}_{2 c}$ 


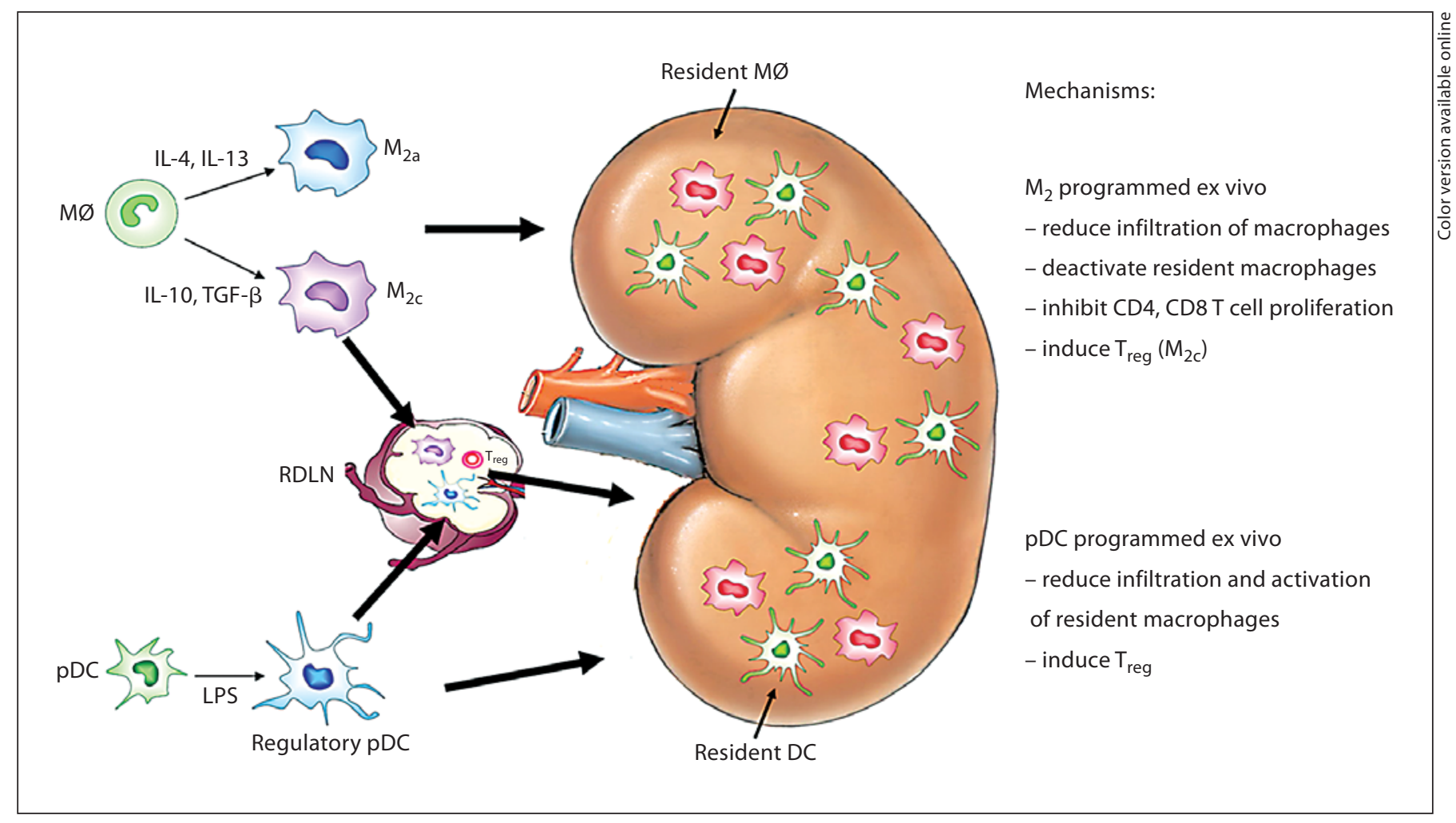

Fig. 1. Mechanisms by which macrophages and DC modify renal disease. Macrophages (MØ) and plasmacytoid dendritic cells ( $\mathrm{pDC}$ ) can be manipulated ex vivo to $\mathrm{M}_{2}$ macrophages $\left(\mathrm{M}_{2 \mathrm{a}}, \mathrm{M}_{2 \mathrm{c}}\right)$ and regulatory $\mathrm{pDC}$, which can migrate to damaged kidney or renal draining lymph nodes (RDLN). In the damaged kidney, $\mathrm{M}_{2}$ macrophages $\left(\mathrm{M}_{2 \mathrm{a}}, \mathrm{M}_{2 \mathrm{c}}\right)$ and regulatory $\mathrm{pDC}$ ameliorate renal in- flammation and enhance tissue remodeling by reducing infiltration and activation of resident macrophages and inhibiting CD4 and CD8 $\mathrm{T}$ cell proliferation. In particular, $\mathrm{M}_{2 \mathrm{c}}$ macrophages and regulatory $\mathrm{pDC}$, but not $\mathrm{M}_{2 \mathrm{a}}$ macrophages, expand regulatory $\mathrm{T}$ cells $\left(\mathrm{T}_{\text {reg }}\right)$ in renal draining lymph nodes, which could protect against renal injury by inhibiting other inflammatory cells. macrophages than $\mathrm{M}_{2 \mathrm{a}}$ macrophages could relate to the fact that $M_{2 c}$ macrophages, but not $M_{2 a}$ macrophages, were shown to induce $\mathrm{T}_{\text {reg }}$ both in in vitro culture and in vivo in renal draining lymph nodes [2] (fig. 1).

The mechanisms underlying the protective effect of $\mathrm{M}_{2}$ macrophages have been investigated in our studies [1, 2]. Both $\mathrm{M}_{2 \mathrm{a}}$ macrophages and $\mathrm{M}_{2 \mathrm{c}}$ macrophages can interact with other cells and in general have similar effects on effector $\mathrm{T}$ cells and macrophages. However as discussed above, $M_{2 c}$ macrophages but not $M_{2 a}$ macrophages can induce $T_{\text {reg. }}$. Both $M_{2 a}$ macrophages and $M_{2 c}$ macrophages can inhibit CD4 $\mathrm{T}$ cell proliferation and reduce $\mathrm{CD} 8$-induced tubule cell cytotoxicity. Both types of $\mathrm{M}_{2}$ macrophages are able to deactivate renal inflammatory $\left(\mathrm{M}_{1}\right)$ macrophages. This ability of $\mathrm{M}_{2 \mathrm{c}}$ macrophages to deactivate $M_{1}$ macrophages has been shown in coculture and was further demonstrated in the AN model by their deactivation of endogenous renal macro- phages. Thus, the protective effects against renal injury may involve their suppression of other immune cells (fig. 1).

As with all cell-based therapy, specificity, sustainability and safety of adoptively transferred macrophages or DC are essential. With regard to the sustainability of protective function of transferred macrophages, we found that suppressive features of $\mathrm{M}_{2}$ macrophages did not diminish during 4 weeks of culture, and that their phenotype in the kidney was maintained for at least 4 weeks after transfusion [1,2]. Another important issue is whether $\mathrm{M}_{2}$ macrophages may have unwanted harmful effects. For example, macrophages are sometimes recognized as having opposing effects on inflammation and fibrosis. This is relevant as a protective anti-inflammatory action of $\mathrm{M}_{2}$ macrophages and could be mitigated by a concomitant profibrotic effect. We showed that during 3 weeks after transfusion of $\mathrm{M}_{2}$ macro- 
phages into an immunocompetent model of $\mathrm{AN}$, the phenotype of transfused macrophages did drift, but not towards a distinct $\mathrm{M}_{1}$ or $\mathrm{M}_{2}$ phenotype. Although $\mathrm{M}_{2}$ macrophages express high levels of TGF- $\beta$, a growth factor linked to renal fibrosis, our recent studies in AN mice treated with $\mathrm{M}_{2}$ macrophages showed a reduction rather than promotion of renal fibrosis. Interestingly, transfused $\mathrm{M}_{2}$ macrophages had persistent anti-inflammatory effects but gradually decreased their secretion of TGF- $\beta$, and thus profibrotic ability, as the disease progressed. In vivo proliferation of transfused $\mathrm{M}_{2}$ macrophages has the potential to alter their phenotype and reduce their protective function. Importantly, in recent studies we showed that $\mathrm{M}_{2}$ macrophages separated from the spleen do not proliferate in in vitro culture for up to 3 weeks, nor do they in vivo in kidneys of mice with AN. In contrast, $\mathrm{M}_{2}$ macrophages derived from bone marrow could not protect against renal injury in $\mathrm{AN}$ and were shown to proliferate in vitro and in vivo in AN kidneys [2].

The advantages of adoptive transfer of cytokine-modified macrophages include the simplicity of ex vivo modulation, preferential targeting of inflamed kidneys and sustained regulatory effects. In comparison to other macrophage strategies such as genetic manipulation or systemic chemokine blockade, cytokine modulation of macrophages to an $\mathrm{M}_{2}$ phenotype provides many of the advantages without associated risks of uncontrolled viral replication and nontargeted immunomodulation.

\section{DC as a Therapeutic Approach}

Renal DC were first described as MHC class II+ cells with stellate and 'mononuclear phagocyte' morphology, confined largely to the renal interstitium and to a small extent to glomeruli. Two different DC subsets, CD68+BDCA-1+DC-SIGN+/- HLA-DR+ myeloid DC and BDCA-2+HLA-DR+ lymphoid DC have been demonstrated in human renal interstitium [9]. DC have also been shown to accumulate in tubulo- or periglomerular interstitium in human lupus nephritis [10] and glomerulonephritis [11], and in rat crescentic glomerulonephritis. Depletion of renal DC aggravated renal histological injury and worsened renal function in a model of nephrotoxic nephritis, indicating a possible regulatory function of DC in renal tissue [12]. However, the actual roles of DC in renal injury are poorly understood.

DC can be modulated to become tolerogenic (regulatory DC) in vitro by IL-10/TGF- $\beta$, vasoactive intestinal peptide or endogenous glycan-binding protein (galectin 1). Regulatory DC have been used to treat experimental autoimmune disease, including rheumatoid arthritis, encephalomyelitis, colitis, diabetes and transplantation rejection. Plasmacytoid dendritic cells (pDC) are another subset of DC that also have been shown capable of suppressing autoimmune diseases and graft-versus-host disease in experimental animal models [13, 14]. To date, there has been little exploration of potential benefits of adoptive transfer of regulatory DC to protect against renal injury (table 1). Our group recently separated pDC from spleen, modulated them ex vivo using cytosinephosphate-guanine or lipopolysaccharide to a regulatory phenotype and then adoptively transferred them into mice with AN. In this study, pDC localized to the renal cortex and reduced injury. Kidneys from AN mice transfused with pDC had less glomerulosclerosis, tubular atrophy and interstitial expansion than did control AN mice. Mice infused with pDC also had significantly less proteinuria and impairment of creatinine clearance. The mechanism underlying the protective effects of $\mathrm{pDC}$ on renal injury in $\mathrm{AN}$ mice was attributed to their ability to transform naïve $\mathrm{T}$ cells into Foxp $3+\mathrm{T}_{\text {reg. }}$. In contrast, $\mathrm{DC}$ derived from bone marrow did not track to damaged $\mathrm{AN}$ kidneys, and had no protective effect.

\section{Unanswered Questions}

\section{Characteristics of Regulatory Macrophages and}

Regulatory DC in vivo

Phenotypes characteristic of different macrophage and DC subsets can be reliably and specifically produced by ex vivo cytokine modulation. However, whether the features of protective $\mathrm{M}_{2}$ macrophages and DC in renal diseases are similar to those of $\mathrm{M}_{2}$ macrophages and DC produced ex vivo is unknown. Studies are under way to accurately define regulatory macrophages and DC in renal disease by extensive examination of their surface molecules, cytokine expression, genetic determinants of regulatory phenotype and suppressive functions.

\section{Relative Efficacy of Subsets of $M_{2}$ Macrophages and DC Subsets}

We have shown that $\mathrm{M}_{2 \mathrm{c}}$ macrophages are more effective than $\mathrm{M}_{2 \mathrm{a}}$ macrophages in ameliorating renal injury in AN. It is unclear whether the relative efficacy of subsets of $\mathrm{M}_{2}$ macrophages depends on characteristics of the particular type of kidney disease, including its dependence on innate versus adaptive immunity. Similarly, the po- 
tency of DC used in adoptive transfer studies could depend on the type of kidney disease. Published research has focused on the effect of $\mathrm{M}_{2}$ macrophages or DC given prior to or early after the onset of renal injury, whereas their effect in advanced disease is not known.

\section{Origin of $\mathrm{M}_{2}$ Macrophages and Regulatory DC}

To date we have demonstrated renoprotective effects of $\mathrm{M}_{2}$ macrophages and regulatory DC derived from spleen. In humans it would be difficult to use spleen-derived cells. Whether $\mathrm{M}_{2}$ macrophages and DC derived from other organs such as bone marrow, peripheral blood or peritoneum have or can be modified to have efficacy for treating renal disease is unknown. However, unlike spleen-derived $\mathrm{M}_{2 \mathrm{a}}$ macrophages, bone-marrow-derived $\mathrm{M}_{2 \mathrm{a}}$ macrophages were not protective and their expression of anti-inflammatory cytokines and regulatory molecules was dramatically reduced in the inflamed kidney. In contrast to bone marrow $\mathrm{M}_{2 \mathrm{a}}$ macrophages and splenic $\mathrm{pDC}, \mathrm{DC}$ derived from bone marrow did not track to inflamed kidney.

\section{Potency of $\mathrm{M}_{2}$ Macrophages and Regulatory DC}

If regulatory macrophages and DC are to be used as a therapy for renal disease, it will be necessary to enhance their potency. Potential methods for enhancing potency of $\mathrm{M}_{2}$ macrophages and regulatory DC include optimizing culture conditions using different cytokine combinations and $\mathrm{T}$ regulatory cell contact, modification using genetic determinants of protective phenotypes or possibly exposure to specific antigens to develop antigen-loaded regulatory DC and $\mathrm{M}_{2}$ macrophages.

\section{Conclusion}

Recent data have demonstrated a protective role for regulatory macrophages and DC in dampening glomerular and tubulointerstitial inflammation in a number of models of renal injury. Ex vivo modulation of macrophages and DC is a novel and effective strategy for treating renal inflammation and injury. Much more needs to be understood about the biology of macrophages and DC before application to human kidney disease can be considered.

\section{References}

1 Wang Y, Wang YP, Zheng G, Lee VW, Ouyang L, Chang DH, Mahajan D, Coombs J, Wang YM, Alexander SI, Harris DC: Ex vivo programmed macrophages ameliorate experimental chronic inflammatory renal disease. Kidney Int 2007;72:290-299.

-2 Cao Q, Wang Y, Zheng D, Sun Y, Wang Y, Lee VW, Alexander SI, Harris DC: IL-10/TGF- $\beta$ modified macrophages induce regulatory $\mathrm{T}$ cells and protect against murine Adriamycin nephrosis. J Am Soc Nephrol 2010;21:933942.

- 3 Yokoo T, Ohashi T, Utsunomiya Y, Shen JS, Hisada Y, Eto Y, Kawamura T, Hosoya T: Genetically modified bone marrow continuously supplies anti-inflammatory cells and suppresses renal injury in mouse Goodpasture syndrome. Blood 2001;98:57-64.

$\checkmark 4$ Kluth DC, Ainslie CV, Pearce WP, Finlay S, Clarke D, Anegon I, Rees AJ: Macrophages transfected with adenovirus to express IL-4 reduce inflammation in experimental glomerulonephritis. J Immunol 2001;166:47284736 .

5 Wilson HM, Stewart KN, Brown PA, Anegon I, Chettibi S, Rees AJ, Kluth DC: Bone-marrow-derived macrophages genetically modified to produce IL-10 reduce injury in experimental glomerulonephritis. Mol Ther 2002; 6:710-717.
6 Wilson HM, Chettibi S, Jobin C, Walbaum D, Rees AJ, Kluth DC: Inhibition of macrophage nuclear factor-kappaB leads to a dominant anti-inflammatory phenotype that attenuates glomerular inflammation in vivo. Am J Pathol 2005;167:27-37.

$\checkmark 7$ Yokoo T, Ohashi T, Utsunomiya Y, Kojima H, Imasawa T, Kogure T, Hisada Y, Okabe M, Eto Y, Kawamura T, Hosoya T: Prophylaxis of antibody-induced acute glomerulonephritis with genetically modified bone marrow-derived vehicle cells. Hum Gene Ther 1999;10:2673-2678.

8 Kryczek I, Zou L, Rodriguez P, Zhu G, Wei S, Mottram P, Brumlik M, Cheng P, Curiel T, Myers L, Lackner A, Alvarez X, Ochoa A, Chen L, Zou W: B7-H4 expression identifies a novel suppressive macrophage population in human ovarian carcinoma. J Exp Med 2006;203:871-881

9 Woltman AM, de Fijter JW, Zuidwijk K, Vlug AG, Bajema IM, van der Kooij SW, van Ham V, van Kooten C: Quantification of dendritic cell subsets in human renal tissue under normal and pathological conditions. Kidney Int 2007;71:1001-1008
10 Fiore N, Castellano G, Blasi A, Capobianco C, Loverre A, Montinaro V, Netti S, Torres D, Manno C, Grandaliano G, Ranieri E, Schena FP, Gesualdo L: Immature myeloid and plasmacytoid dendritic cells infiltrate renal tubulointerstitium in patients with lupus nephritis. Mol Immunol 2008;45:259-265.

11 Segerer S, Heller F, Lindenmeyer MT, Schmid H, Cohen CD, Draganovici D, Mandelbaum J, Nelson PJ, Grone HJ, Grone EF, Figel AM, Nossner E, Schlondorff D: Compartment specific expression of dendritic cell markers in human glomerulonephritis. Kidney Int 2008;74:37-46.

12 Scholz J, Lukacs-Kornek V, Engel DR, Specht S, Kiss E, Eitner F, Floege J, Groene HJ, Kurts C: Renal dendritic cells stimulate IL-10 production and attenuate nephrotoxic nephritis. J Am Soc Nephrol 2008;19:527-537.

13 Hadeiba H, Sato T, Habtezion A, Oderup C, Pan J, Butcher EC: CCR9 expression defines tolerogenic plasmacytoid dendritic cells able to suppress acute graft-versus-host disease. Nat Immunol 2008;9:1253-1260.

14 Bailey-Bucktrout SL, Caulkins SC, Goings G, Fischer JA, Dzionek A, Miller SD: Cutting edge: central nervous system plasmacytoid dendritic cells regulate the severity of relapsing experimental autoimmune encephalomyelitis. J Immunol 2008;180:6457-6461. 